\title{
COMPARISON OF ROLLING MILL DRIVE SHAFT CONCEPTS*
}

Peter Grawenhof ${ }^{1}$

\begin{abstract}
Universal joint shafts and slipper spindles are commonly used in rolling mills to compensate the design- and process-related offset between the motors and work rolls. Although both types of shafts exhibit on the same kinematic principle, there are basic differences regarding the design concepts. These differences become noticeable on many levels and may become very distinct in terms of Life-Cycle-Costs (LCC). In this respect, a critical comparison between universal joint shafts and slipper spindles can be made.

Keywords: Universal-joint shafts; Slipper spindles; Efficiency; Life-cycle-costs; Carbon footprint; Lubrication.
\end{abstract}




\section{INTRODUCTION}

In the steel industry as well as in the nonferrous metal industry, a product passes numerous, complex production cycles. One key process is rolling, i.e. the plastic deformation of raw material into a product with specific shape and material properties such as steel strip for the automotive industry, beams for civil engineering or wire for tire manufacturing (Figure 1). The constant demand for increased productivity and improved product quality creates higher loads in rolling mills, especially the process-related forming forces transmitted by the drive system. In order to keep rolling forces low, mill builders try to keep the work roll diameter as small as possible. However, this reduces the available installation space of the drive shafts, which have to fit within the rotating diameter of the work rolls. Still torque transmitting drive trains are expected have a long lifetime, low risk of failure together with low maintenance requirements. Moreover drive shafts are required to have a high efficiency of power transmission in order to minimize energy losses. The sum of requirements, i.e. rising productivity, product quality, high machine lifetime and energy efficiency necessitates the selection of an optimal drive concept for the respective type of rolling mill with a special focus on LCC (also referred to as TotalCost-of-Ownership / TCO). This paper elaborates on the two most common types of joint shafts connecting driving side (motor or gear box) and driven side (rolls): Universal joint shafts and slipper spindles in the light of the demanding operating onditions prevailing in rolling mills.

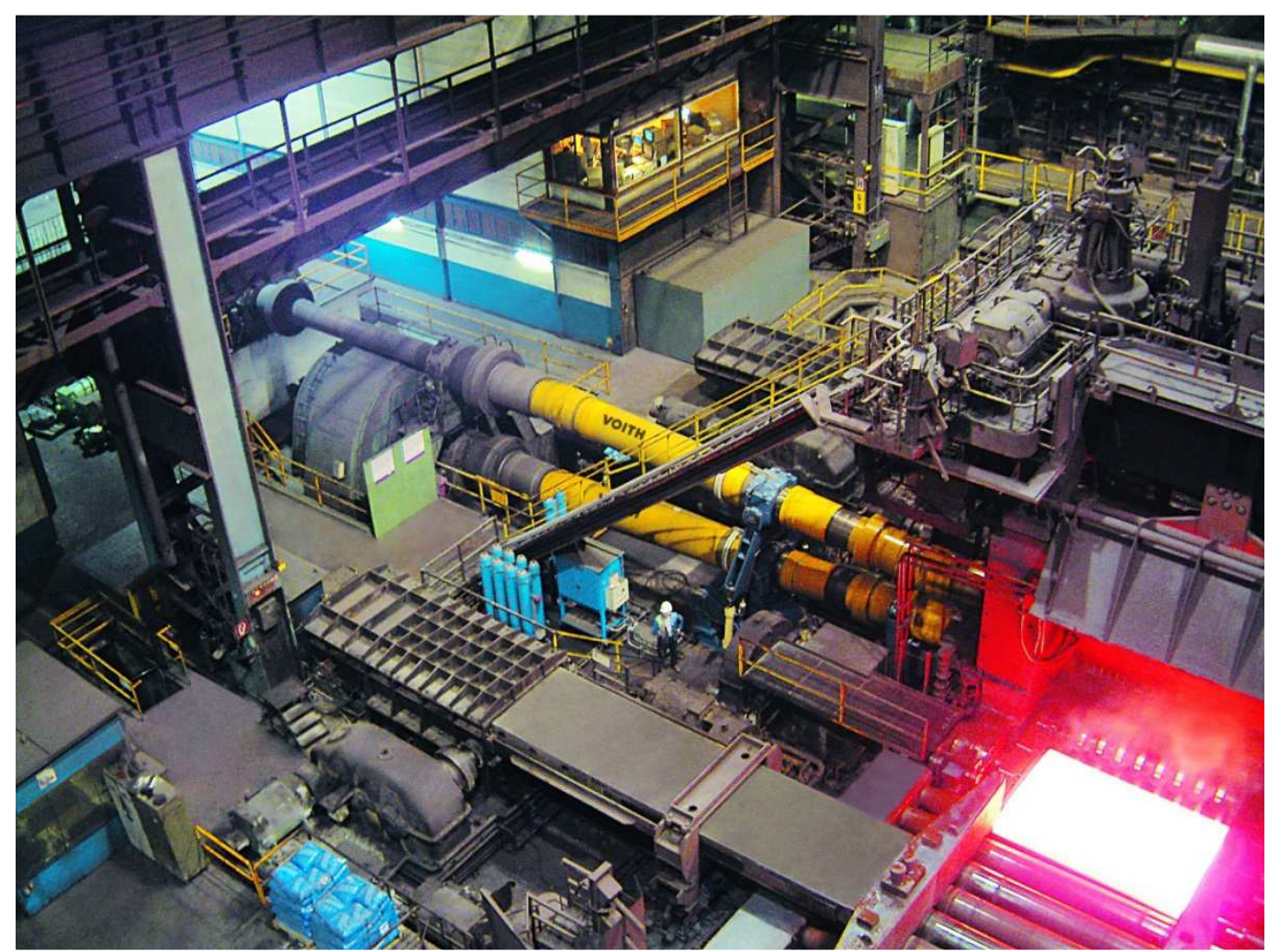

Figure 1: Heavy plate rolling mill in operation 


\section{MATERIAL AND METHODS}

\subsection{Rolling Mill Main Drive Shafts}

Design- and process-related, an offset between drive (motor or gear box output shaft) and working units (roll) of rolling stands is bridged by means of so called joint shafts. Normally, these consist of two articulating joints that are connected with an intermediate shaft, whereas the deflecting or bending of the articulating joints allows compensating misalignment and displacement between input and output axis, thus providing constant "flow" of torque and rotation (Figure 2).

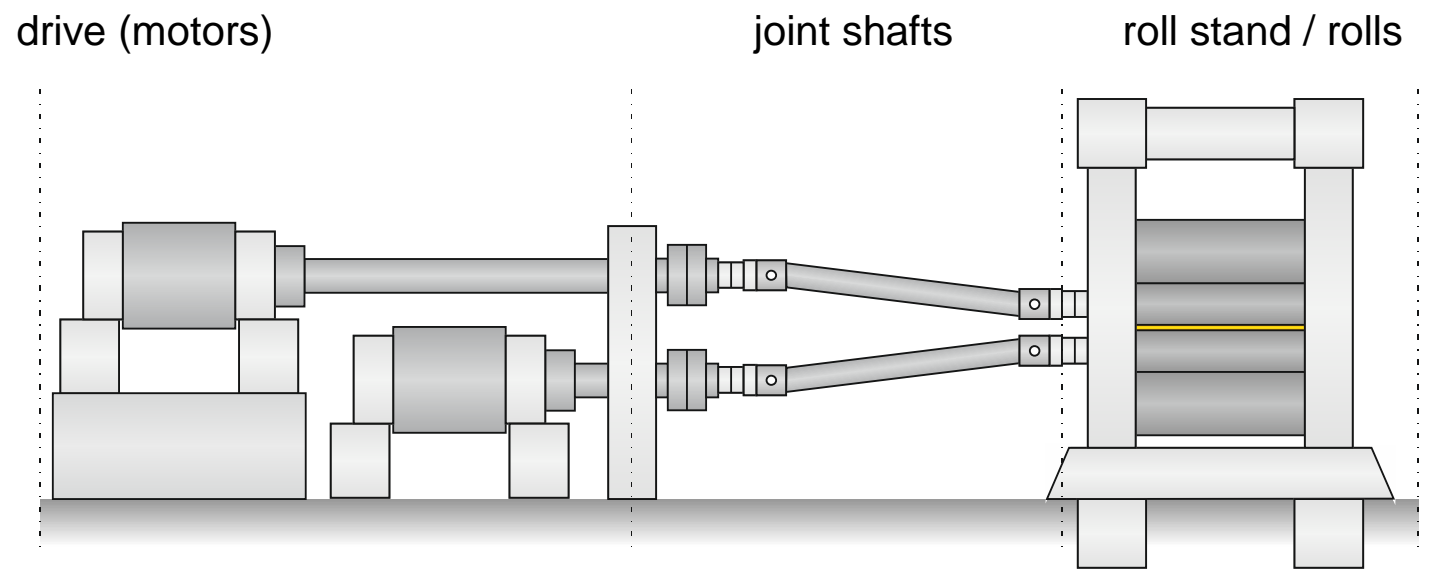

Figure 2: Principal layout of a rolling mill main drive (twin drive)

With regard to the structural design of joint shafts, universal joint shafts (UJS, also referred to as cardan shafts) and slipper spindles (or flat neck spindles FNS) are well established for rolling mill applications, [1]. A third type of joint shafts, so called gear spindles, is sometimes used in rolling mill main drives too. However, these only allow small deflection angles due to their design, and thus not included as object of the considerations.

Each articulated joint consists of two halves and an intermediate component being mounted pivoting between the articulating joint halves, thus enabling the bending of the joint (Figure 3). This intermediate element is referred to as journal cross for universal joint shafts and slipper pads in case of slipper spindles. Contrary to universal joints on which the journal cross is supported by antifriction bearings, the slipper pads of slipper spindles carry their movement via sliding surfaces which involves friction. Although the design principles from the kinematic view are identical, the differing bearing variants leads to fundamentally different operating conditions, [2]. As a consequence, when planning or optimizing a rolling mill main drive, the respective advantages and disadvantages of universal joint shafts and slipper spindles need to be considered for the individual case of application.

\subsection{Efficiency of Power Transmission}

Ideal power transmission unfortunately does not exist in mechanics. Friction occurs and thus a portion of the transmitted power is lost as heat, plastic deformation, abrasion etc. The amount of the dissipated energy and thus the energy losses incurring while operating rolling mill main drives, are directly related to the power transmission efficiency of the used type of joint shaft. Regarding efficiencies, it turns 
out that it is almost $100 \%$ for universal joint shafts (UJS) whereas the power transmission efficiency of slipper spindles varies between $97.2 \%$ and $99.4 \%$ depending on the operating conditions, the deflection angle and the lubrication system (Figure 4) [1,3].

The reason for the efficiency differences between universal joint shaft and slipper joints is due to the type of bearing required on the intermediate element. On account of the rolling friction principle, the antifriction bearings mounted to the journal cross of a universal joint shaft allows for very high, virtually torque-independent efficiencies whereas the sliding friction of a slipper joint, is subject to mixed friction conditions, which reduces power transmission efficiency significantly.

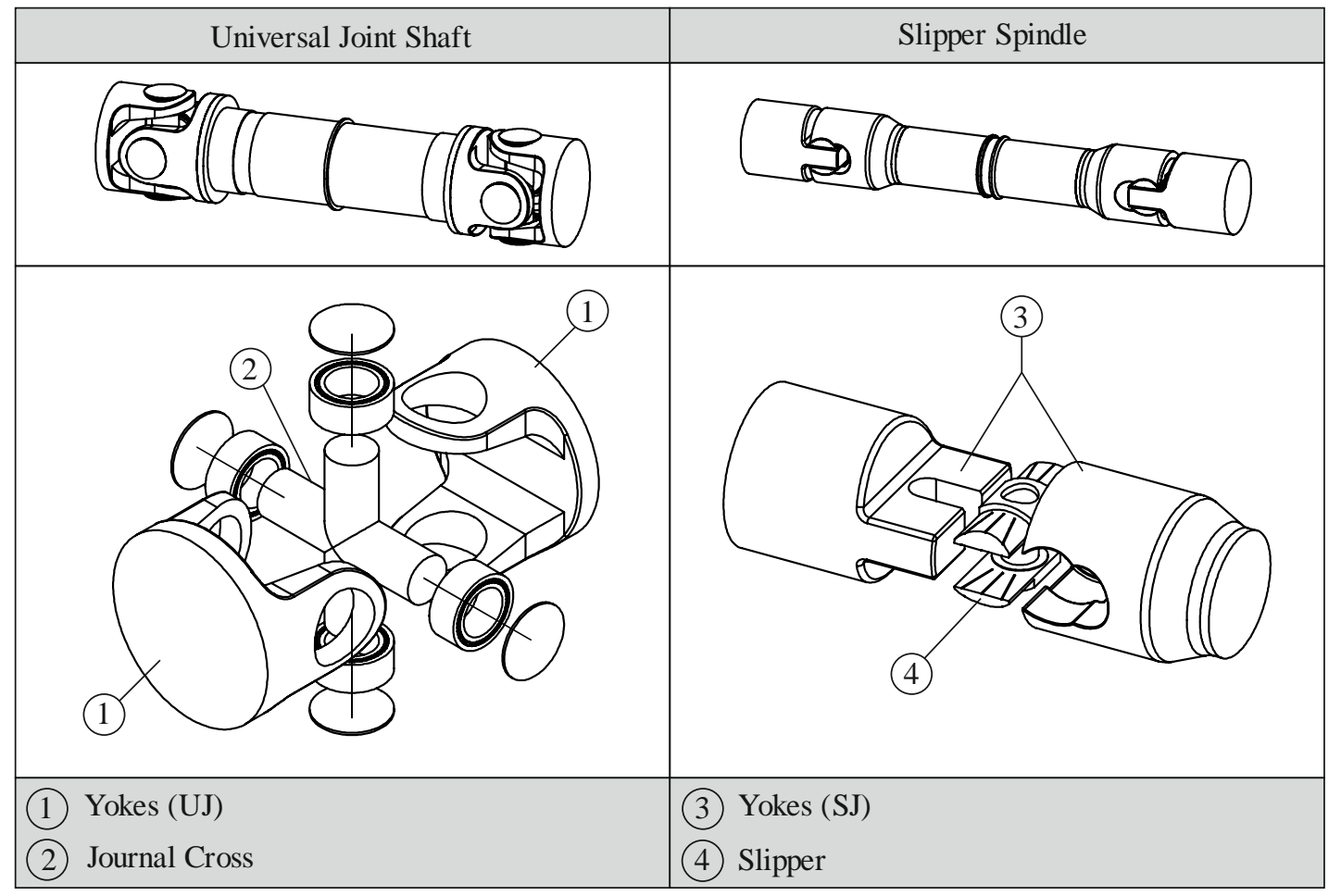

Figure 3: Structural design of universal joint shafts and slipper spindles in principle

The much lower efficiency level of a slipper joint causes a not insignificant increase in energy costs during operation when compared to a universal joint. The commonly used grease lubricated type slipper spindles can show up to 40 times higher energy losses when compared to universal joints. Of course, in practice it's not the relative energy difference that should be compared, but the absolute level of energy losses considered in a Life-Cycle-Cost assessment. As rolling mill drives are some of the most powerful machines in heavy-duty mechanical engineering, considerable energy cost savings can be achieved if universal joint shafts are used instead of slipper spindles in the drive train [1]. This is presented by the following example from practice:

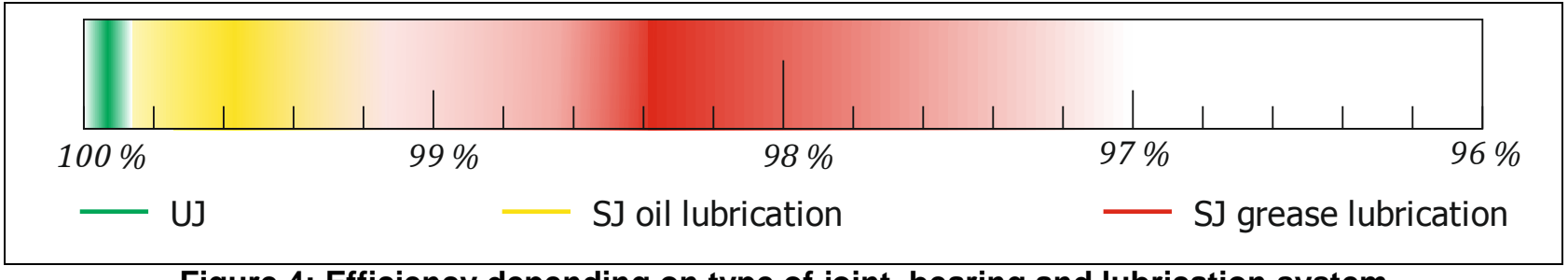

Figure 4: Efficiency depending on type of joint, bearing and lubrication system 
A plate mill rolling stand driven by two motors with an input power of $10000 \mathrm{~kW}$ each, with $200 \%$ short-term overload capacity and an annual contact time of $25 \%$ of $6500 \mathrm{~h}$ yearly operating time, is upgraded from a drive solution with slipper spindles $\left(\eta_{F S Z}=\right.$ 99,1\%), where oil-grease lubrication (roll side slipper joint grease lubricated, and motor side slipper joint oil lubricated) is used, to universal joint shafts $\left(\eta_{K G W}=\right.$ $99,996 \%$ ). The mill operator saves up to $290.000 €$ per year on energy costs alone (at an energy price of $25 \mathrm{ct} / \mathrm{kWh}$ ). When replacing grease-grease lubricated type slipper spindles, energy cost savings will be much higher and, under certain circumstances, could exceed the initial investment costs for a slipper spindle after a few years of operation. Along with energy cost savings, the carbon footprint of the rolling mill will be improved.

\subsection{Investment and Maintenance Costs}

Investment and maintenance costs of slipper spindles and universal joints can differ significantly. Expenses for procurement of a universal joint shaft are typically higher than the initial purchase price of a slipper spindle of standard design and performance. Although slipper spindles manufactured by a premium supplier with maximum torque capacity and fully equipped with complex oil lubrication systems may exceed the investment cost of a universal joint shaft of similar torque rating [1].

When considering overall Life-Cycle-Costs, expenses for the lubrication system of the joints can have a significant impact on the maintenance costs of the drivelines. Lubrication requirements of a universal joint shaft are clearly less costly than the one of a type slipper spindle, due to its hermetically sealed roller bearings, which only require routine re-greasing, i.e. on a monthly basis. In contrast slipper spindles require continuous lubrication of the friction gaps - either by integrated grease pumps or by feeding lubricant via a rotary feedthrough. The recently introduced oil-air lubrication systems for slipper spindles is the most efficient way to lubricate slipper type joints, however, environmental and health aspects need to be seriously considered, as the oil dissipates as an aerosol out of the system, and thus potentially dangerous lubricant vapors can occur.

Spare parts need individual consideration when life-cycle-costs are considered. Besides energy efficiency costs, spare part expenses have a major impact on the total cost of ownership. Slipper spindles spare parts, primarily the slippers (often referred to as pads) require frequent replacement. Typical maintenance cycles for slipper pads are 6 months. The major overhaul of a universal joint implicates the replacement of the roller bearings (which may include the journal cross in case the rollers run directly on the journal cross, i.e. without inner race). On average, roller bearings in universal joints have a life expectation of between 4 to 8 years. In either case an individual assessment of spare part costs should be considered during the initial investment and procurement stage, especially as maintenance cycles are heavily influenced by the operating conditions.

\subsection{Life-Cycle-Costs}

Life-cycle-costs of rolling mill main drives are primarily influenced by three factors:

1. Purchasing costs for initial equipment

2. Energy efficiency, i.e. power losses generated by the joint shafts

3. Spare parts costs

Energy losses are not typically considered when life-cycle-costs for a rolling mill main drive are assessed. However, during a typical lifespan of a rolling mill main drive (i.e. 
20 to 30 years), energy losses produced by slipper spindles may add up to several times the initial investment costs of the shafts.

Lubrication costs are certainly not negligible either when comparing the drive concepts, when considering the aforementioned factors though, they can seem marginal. However the environmental and health aspects of the various lubrication concepts should be taken into consideration.

The Dresden Technical University carried out interviews with numerous rolling mill operators, which helped to confirm the above statements. The interviews were based on a questionnaire elaborating on the cost aspects related to a specific mill operation. Rolling mills in Asia and Europe and of different types (i.e. plate mills, hot strip mills etc.) were considered. For a systematic analysis of the responses a so called TCO tool was programmed (Figure 5). This software tool is able to support mill project managers and decision makers with the selection of the most optimum drive concept for any type of rolling mill.

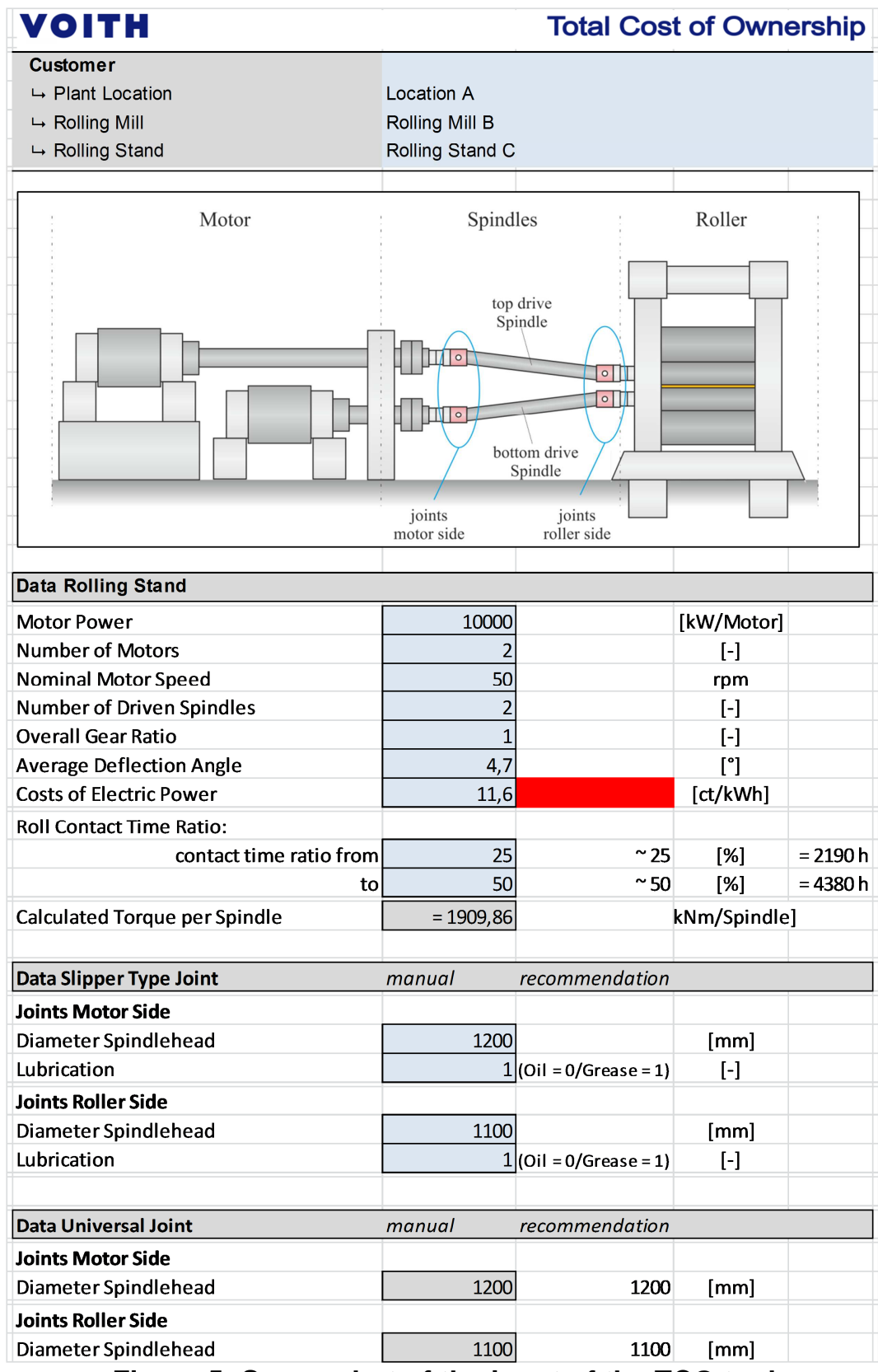

Figure 5: Screenshot of the input of the TCO tool 
An overall comparison comprising of investment and operating costs based on a rolling mill is shown in Figure 6 for both types of joint shafts with grease lubrication. Although exemplary, the graphical result depicts the major characteristics of a TCO assessment:

1. The initial value at year " 0 " is the respective purchasing costs for the slipper spindle (blue line) respective of the universal joint (green line). In this example the initial capital investment of the slipper spindle is about $60 \%$ of the purchasing cost of the universal joint shaft.

2. The step change cost increases are caused by maintenance interval and spare part costs. The slipper spindles requiring half-yearly replacement of the slipper pads at the roll side joint and have a yearly interval at the motor side joint. In contrast the universal joint bearings are replaced after 3, 9 and 15 years. Compared to the 6 year replacement cycle, the replacement of the original equipment roller bearings is a preventive maintenance measure practiced by the mill maintenance staff. After evaluation of the roller bearing condition after the initial 3 years of operation, the maintenance interval was extended to 6 years.

3. The incline of the curve (without the steps from maintenance costs) is mainly defined by efficiency of transmission. Lubrication costs have a smaller influence on the gradients of the curves.

After approximatively 5 years of operation a break-even point is achieved and after 20 years the Life-Cycle-Costs of the slipper spindle are almost double the TCO's of the universal joint. Taking an investment decision on the purchasing price alone would, in this specific case, be the wrong decision. Even including spare part costs would have led to a poor investment decision. Again, the energy efficiency of a rolling mill main drive has a significant impact on its overall costs of operation. The optimum decision, in this example, would have been to invest in universal joints - which in addition give the advantage of a backlash-free drive train and an environmentally friendly operation.

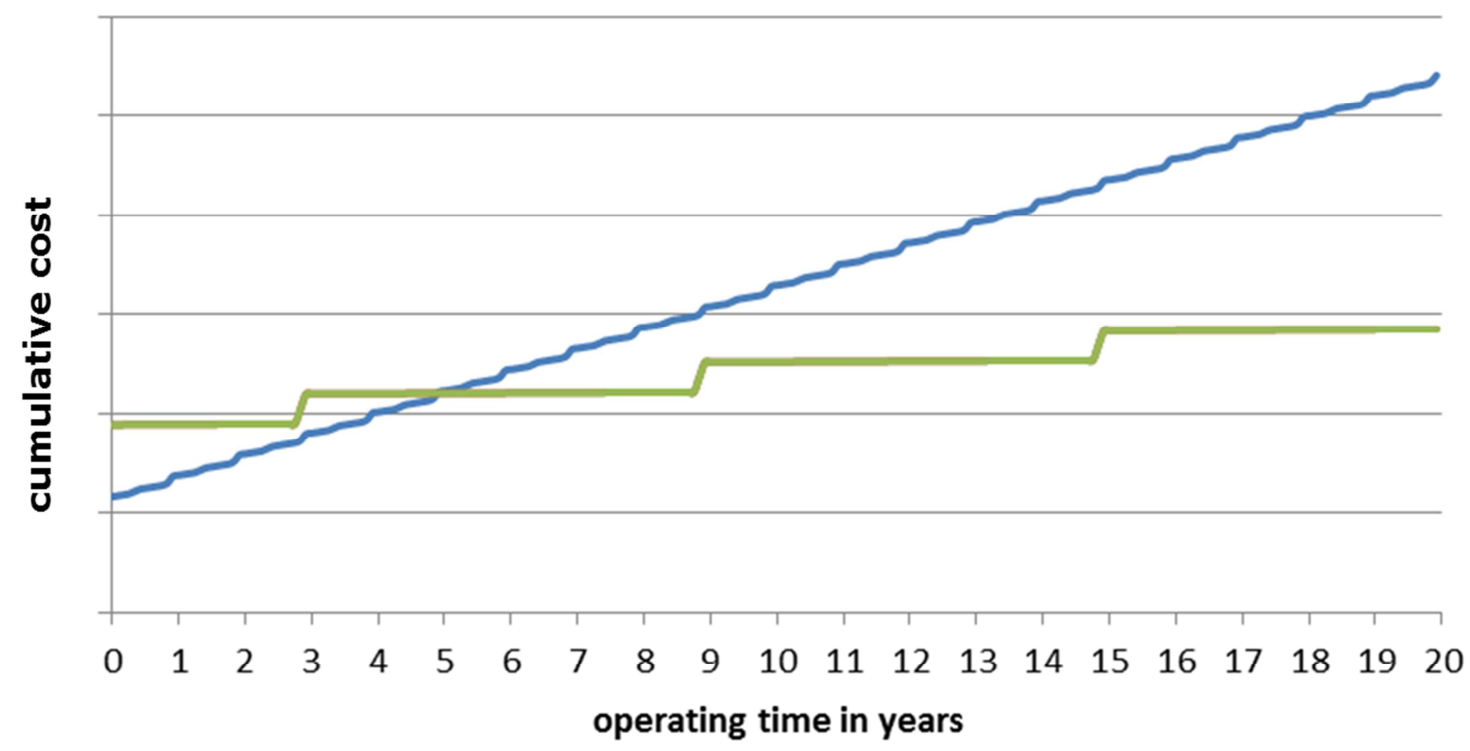

- Slipper Spindles Universal Spindles

Figure 6: Development of Total-Costs-of-Ownership in comparison 


\section{CONCLUSION}

Universal joint shafts have distinct advantages when Life-Cycle-Costs are considered. Compared to slipper spindles, the most significant advantage of universal joint shaft is its higher efficiency resulting from the use of anti-friction bearings in the joints (compared to the friction surfaces of a slipper joint). Due to the higher power transmission efficiency, energy savings can quickly offset the potentially lower purchasing cost of slipper spindles. Typically life-cycle-cost breakeven point is reached after only a few years of operations.

In addition, the encapsulated lubrication system of a universal joint avoids to the greatest extend lubricant being spilled or sprayed to the mill periphery - an environmental contamination typical for slipper spindles. Thus, rolling mills using universal joint shafts have a superior carbon footprint and minimized risk for the environment and for health.

Slipper spindles benefit from their massive joint design, which provides relatively high power density and resistance to load peaks. However recent developments in universal joint shaft technology allow fatigue limits comparable or even superior to slipper spindles to be reached. Regarding the effective peak load capacity of a universal joint, the maximum brinelling load of roller bearings has to be considered as a limit. A highly beneficial aspect of roller bearings is their virtually clearance-free design, thus reducing torque amplification at bite impact and minimizing the risks of torsional vibrations in the driveline.

Summarized, universal joints should be the first choice for rolling mill main drives due to their lower Life-Cycle-Costs and environmental as well as operational aspects.

\section{REFERENCES}

1 Schlecht, B.; Graneß, H.; Rosenlöcher, T.: Vergleich von Kardangelenkwellen und Flachzapfenspindeln. TU Dresden, Lehrstuhl für Maschinenelemente, Forschungsbericht, 2014

2 Seher-Thoss, H. Ch. Graf von; Schmelz, F.; Aucktor, E.: Gelenke und Gelenkwellen. Berechnung, Gestaltung, Anwendungen. 2. Aufl. Berlin Heidelberg: Springer-Verlag, 2002

3 Inoue, N.; Kaneko, S.; lizima, K.: Power Saving in Hot Strip Mill Drives by means of Universal Joints. In.: Transactions ISIJ (1984), Nr. 24, S. $833-837$

4 Mackel, J.: Rolling Mill Main Drive Spindles. Vortrag auf AISTech 2011, Indianapolis, Indiana, USA.

5 Paluh, J.; Hills, G.; Wojtkowski, T.: Design and selection of universal joints for rolling mills. In: Iron \& Steel Technology (1997), Nr. 12, S. 42 - 48 